\title{
Coulisses
}

Revue de théâtre

1 | Printemps 1990

Varia

\section{Itinéraire d'un jeune auteur : fragments}

Jean-Luc Lagarce

\section{(2) OpenEdition}

Journals

Édition électronique

URL : http://journals.openedition.org/coulisses/1545

DOI : $10.4000 /$ coulisses. 1545

ISSN : 2546-9460

\section{Éditeur}

Presses universitaires de Franche-Comté

\section{Édition imprimée}

Date de publication : 1 avril 1990

Pagination : 27-29

ISSN : 1150-594X

\section{Référence électronique}

Jean-Luc Lagarce, «Itinéraire d'un jeune auteur : fragments », Coulisses [En ligne], 1 | Printemps 1990 mis en ligne le 04 juillet 2017, consulté le 22 octobre 2019. URL : http://journals.openedition.org/ coulisses/1545 : DOI : 10.4000/coulisses. 1545

Ce document a été généré automatiquement le 22 octobre 2019

Coulisses 


\title{
Itinéraire d'un jeune auteur : fragments
}

\author{
Jean-Luc Lagarce
}

NOM : LAGARCE

PRÉNOM : JEAN-LUC

ANNÉE DE NAISSANCE : 1957

ÉTUDES UNIVERSITAIRES : Maîtrise de philosophie : " Théâtre et pouvoir en Occident » $-1981$

FORMATION : Conservatoire Régional de Besançon, Elève de Jacques Fornier, Centre de Rencontres

PROFESSION : Auteur - Metteur en scène - Adaptateur

SIGNE DE DISTINCTION : Boursier du Centre National des Lettres : 1983, 1988-89

1 Je n'ai jamais écrit que du théâtre. Il y a des gens qui viennent au théâtre après avoir écrit autre chose, des romans, de la poésie, même s'ils n'ont pas été publiés. Moi, je n'ai rien écrit d'autre...

2 J'ai écrit ma première pièce à dix-huit ans et elle a été enregistrée presque tout de suite à France-Culture. C'était paraît-il très novateur par rapport à ce que le comité de lecture recevait. Je pense que ce n'était pas très novateur mais je devais tellement peu savoir comment s'écrivait une pièce de théâtre qu'on a pensé que j'avais inventé quelque chose. En fait, à l'époque, je n'avais aucun projet littéraire. Je voulais être comédien comme quatre-vingts pour cent des adolescents à un moment ou à un autre.

J'étais en fac, je faisais des études; parallèlement j'allais au Conservatoire. Avec quelques copains, on a décidé de former une troupe amateur mais je n'avais pas l'idée de devenir professionnel un jour.

4 Le gros problème des groupes amateurs, c'est le répertoire parce que soit vous n'êtes jamais le nombre qu'il faut par rapport à une pièce existante, ou alors si le nombre $y$ est, vous ne correspondez pas au rôle. Comme j'avais griffonné des choses, on a pensé que le mieux était d'écrire une pièce pour nous, du sur mesure. L'écriture théâtrale, c'est venu un peu comme ça, très simplement. 
5 Ma première pièce a été enregistrée puis éditée. Quand on a dix-huit ans et qu'on est publié, on croit que ça va durer toute la vie. C'est vrai, j'ai eu un parcours très confidentiel au départ mais c'était France- Culture et j'étais inscrit dans un métier.

6 J'étais dans une toute petite maison d'édition - j'y suis toujours d'ailleurs - qui travaillait également dans la production de théâtre radiophonique, ce qui fait que toutes les pièces que j'ai mises en scène ont été enregistrées à la radio.

7 J'ai écrit une pièce qui a été sélectionnée par le comité de lecture de la Comédie Française pour le petit Odéon qui est une toute petite salle où l'on produit des œuvres d'auteurs contemporains. Ça s'est très bien passé... Après, j'ai enchaîné un certain nombre de spectacles sur des textes que j'ai écrits ou que j'avais envie de monter... J'ai fait un texte - De Saxe, roman - qui a été une véritable catastrophe... J'ai décidé de ne plus mettre en scène les pièces que j'écrivais...

\section{À propos de Music-Hall. À bâtons rompus}

\section{Le marécage}

8 Music-Hall, c'est une pièce sur les acteurs, une espèce de condensé de tout ce qui ne marche pas dans un théâtre. C'est parti d'une sorte de rogne. Vous savez, il y a une expression que j'emploie toujours quand j'ai l'impression de ne plus rien pouvoir faire, quand ça ne va pas, je dis : « c'est le marécage ». Music-Hall, c'est un peu ça... des acteurs qui racontent leur malheur en attendant que le public arrive et le public ne vient pas... C'est du bas de gamme.

9 La chose qui me fait le plus hurler dans un théâtre en tournée, c'est les pompiers.

10 Quand on est acteur, metteur en scène, l'angoisse c'est les pompiers qui sont dans la coulisse, qui parlent, font du bruit, ont un avis. Il n'y a rien de pire. Alors dans la pièce, la comédienne parle des pompiers...

\section{Âge et perspective dramatique}

11 À France-Culture, c'est Judith Magre qui a enregistré le rôle. Elle a fait un enregistrement extrêmement dynamique; il n'y a pas tous ces blancs qui sont dans le spectacle sur scène. C'est beaucoup plus enlevé, alors c'est drôle. Sur scène, je ne trouve pas que ce soit très drôle. Et le choix d'Hélène Surgère pour interpréter le rôle accentue l'effet de mélancolie. Au départ, le personnage féminin était une actrice d'une trentaine d'années; l'idée d'une comédienne jeune racontant que rien ne va, ça n'est pas dramatique; on se dit que ça va s'arranger. Tandis qu'une femme de soixante ans entourée de deux hommes très jeunes qui vont la lâcher, ça raconte une toute autre histoire, l'usure, la fatigue, l'histoire d'une fin. Là, ça fait trente ans que c'est la descente.

Dans le texte, il y avait des indications d'âge. Je ne voulais pas modifier le texte: l'actrice disant : «il y a dix ou quinze ans... » laisse entendre qu'elle est encore jeune alors qu'on voit bien qu'elle ne l'est plus. Mais un jour, en répétition, Hélène Surgère a dit: «il y a vingt ou trente ans...» comme ça spontanément et on a gardé la modification. 


\section{La robe d'Hélène Surgère, ou l'enfer d'un directeur de théâtre}

Il faut quelqu'un pour accrocher la robe depuis le bas du dos et l'enlever à la fin du spectacle. On pourrait croire que ça prend cinq minutes; ça prend exactement trois heures. Hélène Surgère s'habille une heure avant d'entrer en scène, se déshabille à sa sortie de scène et, entre-temps, la personne chargée de l'agrafage attend. Vous avez tous les jours dans le théâtre quelqu'un qui s'appelle une habilleuse et que vous payez non pas cinq minutes mais trois heures, ce qui est normal. Tout travail mérite salaire comme dit mon père. L'habilleuse, elle coûte huit mille francs par mois. Ça fait trois jours qu'on parle de cette habilleuse et il faut la trouver... Diriger un théâtre, c'est un enfer ; il y a mille choses à régler par jour. Aujourd'hui, c'est l'habilleuse...

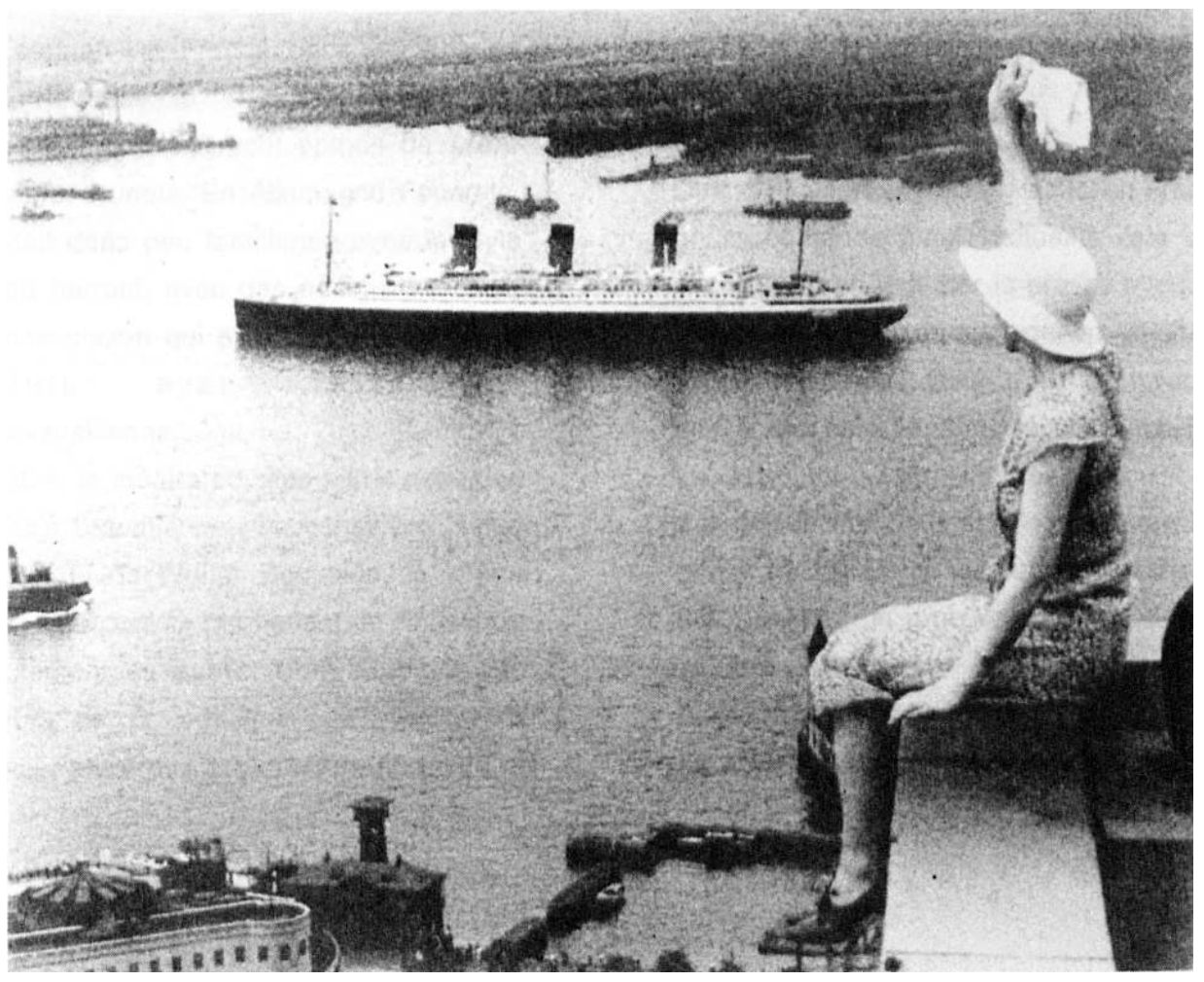

L'affiche de Music-Hall. 